\title{
THE BOUNDEDNESS AND ESSENTIAL NORM OF THE DIFFERENCE OF COMPOSITION OPERATORS FROM WEIGHTED BERGMAN SPACES INTO THE BLOCH SPACE
}

\author{
YANHUA ZHANG AND LIXU ZHANG
}

Abstract. A new characterization for the boundedness of the difference of composition operators $C_{\varphi}-C_{\psi}$ from weighted Bergman spaces into the Bloch space in terms of the Bloch norm of the quantities $\varphi^{n}-\psi^{n}, n \in \mathbb{N}$, is given, as well as an asymptotic estimate for the essential norm of the operator.

Mathematics subject classification (2010): 30H30, $47 \mathrm{~B} 33$.

Keywords and phrases: Bloch space, weighted Bergman space, difference of composition operators, boundedness, essential norm.

\section{REFERENCES}

[1] E. BERKSON, Composition operators isolated in the uniform operator topology, Proc. Amer. Math. Soc. 81 (1981), 230-232.

[2] J. Bonet, M. Lindström And E. Wolf, Differences of composition operators between weighted Banach spaces of holomorphic functions, J. Austral. Math. Soc. 84 (2008), 9-20.

[3] C. Cowen And B. MacCluer, Composition Operators on Spaces of Analytic Functions, CRC Press, Boca Raton, FL, 1995.

[4] T. Hosokawa And S. OHno, Differences of composition operators on the Bloch spaces, J. Operator Theory 57 (2007), 229-242.

[5] Q. HU, S. LI AND Y. SHI, A new characterization of differences of weighted composition operators on weighted-type spaces, Comput. Methods Funct. Theory 17 (2017), 303-318.

[6] Z. JiAng AND S. STEVIĆ, Compact differences of weighted composition operators from weighted Bergman spaces to weighted-type spaces, Appl. Math. Comput. 217 (2010), 3522-3530.

[7] S. LI, Differences of generalized composition operators on the Bloch space, J. Math. Anal. Appl. 394 (2012), 706-711.

[8] S. Li, R. QIAN AND J. ZHOU, Essential norm and a new characterization of weighted composition operators from weighted Bergman spaces and Hardy spaces into the Bloch space, Czechoslovak Math. J. 67 (2017), 629-643.

[9] S. Li AND S. STEVIĆ, Weighted composition operators from Bergman-type spaces into Bloch spaces, Proc. Indian Acad. Sci. Math. Sci. 117 (2007), 371-385.

[10] S. Li AND S. STEvić, Products of composition and integral type operators from $H^{\infty}$ to the Bloch space, Complex Var. Elliptic Equ. 53 (5) (2008), 463-474.

[11] X. LIU AND S. Li, Norm and essential norm of a weighted composition operator on the Bloch space, Integr. Equ. Oper. Theory 87 (2017), 309-325.

[12] K. Madigan And A. Matheson, Compact composition operators on the Bloch space, Trans. Amer. Math. Soc. 347 (1995), 2679-2687.

[13] A. Montes-Rodriguez, The essential norm of a composition operator on Bloch spaces, Pacific. J. Math. 188 (1999), 339-351.

[14] P. Nieminen, Compact differences of composition operators on Bloch and Lipschitz spaces, Comput. Method Funct. Theory 7 (2007), 325-344.

[15] J. ShAPIRO AND C. SundBerG, Isolation amongst the composition operators, Pacific J. Math. 145 (1990), 117-152. 
[16] Y. SHI AND S. LI, Essential norm of the differences of composition operators on the Bloch space, Math. Ineq. Appl. 20 (2017), 543-555.

[17] Y. SHI AND S. LI, Differences of composition operators on Bloch type spaces, Complex Anal. Oper. Theory. 11 (2017), 227-242.

[18] S. STEVIĆ, Essential norms of weighted composition operators from the $\alpha$-Bloch space to a weightedtype space on the unit ball, Abstr. Appl. Anal. 2008 (2008), Article ID 279691, 11 pages.

[19] S. STEVIĆ, On a new integral-type operator from the weighted Bergman space to the Bloch-type space on the unit ball, Discrete Dyn. Nat. Soc. 2008 (2008), Article ID 154263, 14 pages.

[20] S. STEVIĆ, Integral-type operators from a mixed norm space to a Bloch-type space on the unit ball, Siberian Math. J. 50 (6) (2009), 1098-1105.

[21] S. STEVIĆ, Norm and essential norm of composition followed by differentiation from $\alpha$-Bloch spaces to $H_{\mu}^{\infty}$, Appl. Math. Comput. 207 (2009), 225-229.

[22] S. STEVIĆ, On a new integral-type operator from the Bloch space to Bloch-type spaces on the unit ball, J. Math. Anal. Appl. 354 (2009), 426-434.

[23] S. STEvić, On an integral-type operator from logarithmic Bloch-type and mixed-norm spaces to Bloch-type spaces, Nonlinear Anal. TMA 71 (2009), 6323-6342.

[24] S. STEVIĆ, Essential norm of differences of weighted composition operators between weighted-type spaces on the unit ball, Appl. Math. Comput. 217 (2010), 1811-1824.

[25] S. STEVIĆ, Norm and essential norm of an integral-type operator from the Dirichlet space to the Bloch-type space on the unit ball, Abstr. Appl. Anal. 2010 (2010), Article ID 134969, 9 pages.

[26] S. STEVIĆ, Weighted differentiation composition operators from the mixed-norm space to the $n$th weigthed-type space on the unit disk, Abstr. Appl. Anal. 2010 (2010), Article ID 246287, 15 pages.

[27] S. STEVIĆ, Essential norm of some extensions of the generalized composition operators between $k$-th weighted-type spaces, J. Inequal. Appl. 2017 (2017), Article No. 220, 13 pages.

[28] S. STEVIĆ AND Z. JiAnG, Compactness of the differences of weighted composition operators from weighted Bergman spaces to weighted-type spaces on the unit ball, Taiwanese J. Math. 15 (2011), $2647-2665$.

[29] S. Stević And A. Sharma, Essential norm of composition operators between weighted Hardy spaces, Appl. Math. Comput. 217 (2011), 6192-6197.

[30] S. Stević, A. Sharma AND A. Bhat, Essential norm of products of multiplication composition and differentiation operators on weighted Bergman spaces, Appl. Math. Comput. 218 (2011), 2386-2397.

[31] M. TJANI, Compact composition operators on some Möbius invariant Banach space, $\mathrm{PhD}$ dissertation, Michigan State University, 1996.

[32] H. Wulan, D. Zheng And K. Zhu, Compact composition operators on BMOA and the Bloch space, Proc. Amer. Math. Soc. 137 (2009), 3861-3868.

[33] R. ZhaO, Essential norms of composition operators between Bloch type spaces, Proc. Amer. Math. Soc. 138 (2010), 2537-2546.

[34] K. ZHU, Operator Theory in Function Spaces, American Mathematical Society, Providence, RI, 2007.

[35] X. ZhU AND W. YANG, Difference of composition operators from weighted Bergman spaces to the Bloch space, Filomat 28 (2014), 1935-1941. 